\title{
Research on the Establishment of Xinjiang Province in the Late Qing Dynasty from the Perspective of Forming the Chinese National Community
}

\author{
Pengcheng Zeng ${ }^{1, *}$ Linpeng Chen $^{1}$ \\ ${ }^{1}$ School of History, Xinjiang University, Urumchi, Xinjiang 830046, China \\ *Corresponding author. Email: 1365507864@qq.com
}

\begin{abstract}
In 1884, the Qing government established provincial system in Xinjiang, which strengthened the direct control of the central government over Xinjiang. This paper takes Zuo Zongtang, Liu Jintang and others' memorials to the founding of Xinjiang Province and their concrete realization process as the starting point of historical data. In the new perspective of building a strong sense of the Chinese community, this paper analyzes the promotion of Xinjiang's founding of the province on building a strong sense of the Chinese community of all ethnic groups in Xinjiang from three aspects: improving China's cognitive experience, cultivating China's values and beliefs, and practicing China's common will.
\end{abstract}

Keywords: Xinjiang region, Zuo Zongtang, Provincial system, The Chinese nation, Sense of community.

\section{INTRODUCTION}

At the 19th National Congress of the Communist Party of China, General Secretary Xi Jinping stressed the need to "build up the sense of the Chinese national community and strengthen exchanges among all ethnic groups" [1]. The Chinese national community is rich in the connotation of the conventional term of the Chinese nation, while the consciousness of the Chinese national community is the subjective mapping to the objective entity of the Chinese national community. On the construction of the consciousness of the Chinese national community, this paper has explored the history of the consciousness of the Chinese national community vertically. And the consciousness of the Chinese national community has different historical characteristics in different historical stages [2]. Especially, this paper discusses the important period of the anti-Japanese War, which is of great significance to the shaping of the consciousness of the Chinese national community [3]. At the same time, this paper explores the elements, distinctive features and the path of forming the Chinese national community from the horizontal perspective
[4]. Also, it is necessary to hold that the Chinese national community is composed of different complexes [5]. It is suggested to focus on the important role of building a common spiritual home of all nationalities in order to firmly shape the consciousness of the Chinese national community [6]. Some scholars use "Manchu Community" [7] and other communities with distinct characteristics in history to explore the formation of the consciousness of the Chinese national community. As a community of free people, the Chinese national community has existed for thousands of years. Since modern times, in the process of jointly resisting imperialist aggression, it has gradually moved towards self-consciousness. However, a large number of studies above rarely fully study the consciousness of the Chinese national community in the specific space and time field of the northwest region since modern times. At present, the academic circles focus on the overall overview of the establishment of Xinjiang provincial system, the evolution of administrative divisions and its historical significance in the late Qing Dynasty [8], lacking the new research perspective.

The government of Qing Dynasty changed the administrative system of military government under 
the indirect control of the original central government in Xinjiang into a provincial system directly governed by the central government. It is of great significance for the people of all ethnic groups in Xinjiang to firmly establish the sense of the Chinese national community and strengthen the national identity of the people of all ethnic groups in Xinjiang. Therefore, the authors believe that the establishment of provincial system of Xinjiang in the late Qing Dynasty will be carried out. It is of historical and practical significance to carry out new research and exploration, tell Xinjiang story and explore the rule of governing Xinjiang and deepening the party's strategy of governing Xinjiang from the perspective of forming the Chinese national community.

\section{A SURVEY OF THE ESTABLISHMENT OF PROVINCIAL SYSTEM IN XINJIANG IN THE LATE QING DYNASTY}

\subsection{The Reasons of Setting Up Provincial System in Xinjiang}

After the Qing government calmed down the Junggar rebellion and recovered the southern Xinjiang, it established the "general governing Ili and other places" in the Ili Area in 1762, and established the "three-in-one" Ili military government system of "Beg government, Zhasake government and prefecture government". The system was based on the principle that the central government of all dynasties in China had the tradition of "improving the religion but not changing the custome, perfecting the politics but not changing the circumstances". According to the customs and historical circumstances of different nationalities, different management methods are adopted, and according to the implementation policy of ethnic segregation, systematic administrative management is carried out in Xinjiang. In the early period of the governance of Xinjiang by the Qing government, this series of systems played a positive role in stabilizing the political rule and maintaining the stable recovery of the economy and people's livelihood. However, in the case of ethnic isolation, the communication and integration of all ethnic groups almost stagnated, hurting the connection of all ethnic groups.
Moreover, due to the rapid corruption of the Qing government, counselors and ministers dispatched in southern Xinjiang collaborated with the local Boke forces to squeeze the local people of all ethnic groups. In 1765, the Wushi area of the southern Xinjiang broke out a civil commotion, coupled with the long-term seclusion of the Qing government. Since the Opium War in 1840, under the long-term invasion of Western imperialism, China under the rule of the Qing government had a serious border crisis. Xinjiang, located in the northwest frontier of China, was not spared and ceded a large amount of territory to tsarist Russia. Thus, the Qing government's rule in Xinjiang area was collapsing day by day, and the people of all nationalities resisted the feudal rule of the Qing Dynasty.

While the people of all ethnic groups in Xinjiang opposed the feudal rule of the Qing government and launched a great uprising, in 1865, Agubai, the military commander of Haohan Khan, took advantage of the name of busuluke, the descendant of Hezuo, and began to invade Xinjiang, and successively occupied Kashgar, Hetian, Yecheng, Aksu, Yanqi, Turpan, Urumqi and other regions, and established the "Hongfu Khan state". The heavy tax was imposed on the people of Xinjiang, and strict religious regulations were set up for civil administration, which completely disintegrated the original administrative system of the Qing Dynasty in the South Xinjiang area. In this chaotic period, in July 1871, the tsarist Russian Empire took advantage of the emptiness and illegally occupied Ili area for more than ten years, and sent a large number of troops, drove out the officials of the Qing Dynasty, established illegal military and political institutions, and ruled the Ili area illegally. So far, the administrative system of the Ili military government in Xinjiang was completely disintegrated.

\subsection{The Process of Establishing Provincial System in Xinjiang}

In the face of the severe situation in Xinjiang, Zuo Zongtang was appointed by the Qing government as the Minister of the imperial government to supervise the military affairs of Xinjiang in May 1875. In April 1876, he took Liu Jintang and Jin Shun as the main generals to recover Xinjiang. In June 1877, the army of Qing Dynasty basically recovered the northern part of 
Xinjiang except Ili area. In his manuscript "overall plan of the whole situation according to the imperial edict", Zuo Zongtang took the national defense security, livelihood economy and border stability as the starting points, indicating the strategic status of Xinjiang region. "Maintaining the state-owned Xinjiang is the general meaning of ancient and modern times. The scale of the construction lies in the organizational system, which is in line with the circumstances. Since ancient times, China has suffered from the border crisis, and the Northwest have been away from the southeast. It is the reason that Xinjiang people pay attach to protecting Mongolia, and protecting Mongolian means to defend the capital." [9] ${ }^{701-702}$ In view of the severe new situation of imperialism, represented by the Tsarist Russian Empire, who wanted to swallow the territory of northern China, Zuo Zongtang thought: "at the present, the situation is severe, and the Russian people expand their territory from west to east, which is connected with the northern border of China, and only the Mongolian part can turn off their attack. It's better to be far away from home, to be ahead of others, and especially to be prepared." [9] ${ }^{702}$ As for the livelihood of the people in Xinjiang, the economic recovery after the war and the military pay, Zuo Zongtang said: "since the rebellion of Hui nationality, the Han and Hui people have died and gone into exile, and the land is desolate. In recent years, the merchants of Qitai, Gucheng and Jimusa, stragglers and disbanded soldiers and aboriginal people gathered to reclaim the land, and reaped a lot. The government and army paid a high price for the land, which saved money. If it is properly managed, the local will have the hope of recovery." $[9]^{703}$ Based on the support of the above arguments, Zuo Zongtang put forward the urgency and importance of establishing provincial system in Xinjiang. He thought: "to draw a long-term and stable policy for Xinjiang and relieve the worries of the imperial court in the west, it is necessary to set up provinces and change counties." [9] ${ }^{703}$

The Qing government also attached great importance to Zuo Zongtang's proposal of establishing a province. However, because of the vast territory and sparse population in Xinjiang, the folk customs were quite different from those of the provinces in the mainland, and other areas in Xinjiang had not been recovered. Zuo Zongtang carefully considered the specific issue of establishing a provincial system. In August 1877, the Emperor issued an edict, which said: "the governor immediately ordered the officers and soliders to work together and consider the situation, at the same time, it is necessary to plan how to save labor for a long time in Xinjiang." [9] ${ }^{704}$ In January 1878, after Liu Jintang initially pacified the southern part of Xinjiang, the reconstruction of the administrative system in Xinjiang had to be put on the agenda. In October 1878, the Qing government issued an edict to ask Zuo Zongtang about the specific issues of establishing the provincial system, saying: "the rule of counties is peopleoriented. Apart from the old departments, prefectures and counties, is it appropriate for other cities to set up provinces? If the government set up a county, is there any person to be governed? Without provinces, is there any other good policy?" $[10]^{155}$

In 1879, the Qing government punished Chong Hou who negotiated with tsarist Russia for "violating discipline and overstepping authority" and asked Zeng Jize to negotiate with tsarist Russia again about "taking back" Ili area. In order to cooperate with Zeng Jize's negotiation with tsarist Russia, Zuo Zongtang prepared for war and went out of Jiayuguan with coffins, preparing to recapture Yili area illegally occupied by Tsarist Russia by force. At the same time, Zuo Zongtang seized the time to clean up the local economy and people's livelihood in Xinjiang, so as to lay a solid economic foundation for the possible war with the Tsarist Russia. "We should build rivers and canals, build castles, open up farmland, clear land, set taxes, set up private schools, and change the currency." $[10]{ }^{464}$ After arduous negotiations, "the Treaty of Ili between China and Russia" was finally signed in 1881, which recovered the control right of Ili region, but ceded nearly 70000 square kilometers of land to the west of Horgos river. In March 1882, the Qing government sent Shengtai to take over the Ili area, so whether Xinjiang should establish a provincial system was put on the agenda.

In view of whether or not to set up a provincial system in Xinjiang, many people with lofty ideals were still in doubt. The representative was the view of Liu Haiao, editor of Hanlin Academy: "Xinjiang has a vast terrain, with Gobi... After the chaos, the registered permanent residence became less. Now if we want to raise a prefecture and county with 
hundreds of villages, and more than 20 cities form a province. I know it is impossible." [11] ${ }^{125}$ However, Zuo Zongtang, who was already in office as governor of Liangjiang, still resisted public opinions and insisted on establishing a provincial system in Xinjiang for direct central administration." In October 1882, he wrote in his manuscript: "In the past, there were generals, counsellors, ministers of affairs, team leaders, accomplices and co-ministers, and the replacement of officers in general was not intensive. However, there are more officers in charge of the army and less officers in charge of the people, which has been biased. There are many people, and it is necessary to set up officials and posts. As far as Xinjiang is concerned, other ethnic groups are forced to settle down, and their native land is newly returned to China. This is not something that can be done by the additional Taoists." [10 $]^{148}$

Finally, in November 1884, the Qing government formally abolished the military government system through several years of preparatory negotiations, established a provincial system in Xinjiang, and named it "new return of native land". In the traditional sense of the western regions, Xinjiang Province was established. It said: "Zuo Zongtang proposed to establish a provincial system, which was divided into prefectures and counties. According to Liu Jintang, Zuo allowed to set up the officials at all levels. According to the proposal, it is necessary to appoint a new governor and a new chief secretary of Gansu and Xinjiang." $[11]^{1838}$ Liu Jintang was appointed as governor and Wei Guangtao was appointed as political envoy, which greatly weakened the real power of the "King of Tsasak County" in Hami region of Xinjiang. Thus, the whole province of Xinjiang was directly managed by civil affairs officials established by the central government.

\section{THE CONTEMPORARY VALUE AND ENLIGHTENMENT OF ESTABLISHING PROVINCIAL SYSTEM IN XINJIANG IN THE LATE QING DYNASTY}

In essence, the consciousness of Chinese national community is a kind of conscious national consciousness, that is, "on the basis of recognizing the common conditions and history of each other's survival and development, Chinese people adhere to the rejuvenation mentality of common good value norms and active maintenance willingness" [12], which is composed of three parts: national cognitive experience, common good value belief and common behavior willingness. At the end of the Qing Dynasty, in Xinjiang, the national consciousness of the people of all ethnic groups was still in the state of ignorant self-identification, which was the identification of the dynasty regime based on the Confucian political culture [13]. However, in essence, the two did not conflict with each other. The former was the result of the revolutionary evolution and the catalysis of modern nationalism of the latter. After the establishment of Xinjiang Province, the Qing government set up a series of measures, including the abolition of Beg government, the reform of the feudal land tax system, the more in-depth dissemination of Chinese culture, and the abolition of the policy of ethnic segregation. Compared with the administrative system under the general government of Ili, the Qing government replaced the indirect rule by direct rule, which connected Xinjiang more closely with the mainland, improved the cohesion and centripetal force of Xinjiang people to the motherland, and casted the Chinese national community consciousness of all ethnic groups in Xinjiang more deeply.

\subsection{Improving People's Cognitive Experience of China in Xinjiang}

China's cognitive experience consists of two parts, namely, national cognition and life experience. People's national cognition comes from descriptive factors based on their own knowledge system, while national life experience comes from their own evaluative factors for this subject, and the two are mutually causal. Descriptive factors provide guidance for evaluative factors, and evaluative elements provide construction basis for descriptive factors. Among them, the absolute factor is the evaluation factor, that is, the people's satisfaction with life in the community.

\subsubsection{The Abolition of Beg System}

Before the establishment of the provincial system, the Beg system in southern Xinjiang allowed Beg at all levels to have a lot of authority in the local area, and all rewards and punishments of the people were at the discretion of the local 
Beg. For a long time, the central government established an indirect ruling relationship with the local people, and there were a large number of local gentry or temple imams in the position of Beg. The Uyghur people couldn't contact with the central government. The Uyghur people established an indirect identity relationship with the central government, with the local Beg as the media. The ordinary people's understanding of the country can only be derived from the local Beg's statement $[9]^{701}$. To a certain extent, it cannot make the public constitute an objective descriptive factor of the state, weakening the public's national cognition reflected by the central government.

During the Qianlong period, when the Qing government just recovered the southern Xinjiang, the Beg system played a certain role in stabilizing the livelihood management of the Uygur people in southern Xinjiang. Although the Beg appointed and removed by the Qing government could not be inherited, there was no restriction on the term of office. Beg often held power for a long time until he died of illness. With the rapid corruption of the Qing government's control in Xinjiang, the counsellors who supervised the local Beg cannot effectively clamp down and often go along with them. As a result, the Begs had a large number of free-tax land and serfs, and they did not need to pay tribute to the central government. However, their exploitation of the people became more and more serious, which greatly weakened people's satisfaction with living in this community, and led to the continuous uprising of the people of all ethnic groups. The Hezhuo family also had certain authority among the religions of Xinjiang. Beg at all levels also had countless ties with the local religion, which led to the long-term invasion of Kashgar, Yeerqiang and Wushi in southern Xinjiang by the military forces of Kokand Khanate, where Beg often played a guiding role. And then, this became the root of the long-term instability of the Qing Dynasty in the control of Southern Xinjiang. The corruption of the government and the war greatly frustrated the Uygur people's life experience in this community. With the recovery of Xinjiang, the peace of war and the establishment of prefectures and counties, and the direct management of Southern Xinjiang by civil affairs officials set up by the central government, the relationship between the people of all ethnic groups and the state had been directly related $[14]^{323}$, which had improved the relationship between the people of all ethnic groups and the government, changed the public's national cognition of the Chinese national community reflected by local government officials.

\subsubsection{The Reform of the Feudal Land Tax System}

Due to the abolition of the Beg system in southern Xinjiang, Begs at all levels occupied a large number of free-tax land granted by the Qing government, and also occupied a large number of farmland in southern Xinjiang. When the provincial system was established, the farmland occupied by Begs was also returned to the jurisdiction of the Qing government. The Qing government leased these cultivated land to the farmers who lost their cultivated land due to the war, and large number of serfs in southern Xinjiang also get the land. "Begs had cultivated land. Since the establishment of counties, many Begs were abolished, and the freetax land was returned to the government. And the serfs paid the tax according to the rules." [14] $]^{403}$ Since the Qing government took back the southern Xinjiang, it unified the tax system of the whole Xinjiang, and also implemented the same policy of "poll tax" as the mainland. Before the reform of the provincial system, the farmers in southern Xinjiang not only had to pay $10 \%$ of the tax to provide military pay for the border troops stationed in Xinjiang, but also had to provide the local Beg with money, that is, pension fees. Although farmers only needed to pay one tenth of the total harvest, local Beg had too much power and always exploited the local people in many ways. For example, "the Qing government levied one tenth, and the Begs levied twice, but the Hui people suffer a lot." [15] Therefore, Zuo Zongtang believed that "for the sake of the livelihood of the people of all ethnic groups in Xinjiang, we have to unify the tax system, implement a-whip method, levy taxes according to the amount of land, and reduce the proportion of tax originally paid to one tenth to one eleventh." $[10]^{518}$ The reform of the feudal land tax system by the Qing government greatly reduced the burden of the farmers in southern Xinjiang. The people of all ethnic groups living under the control of the central government had a certain improvement in their satisfaction with the Qing government. The better life experience made the people in Xinjiang improve their cognitive experience of the country, 
and promoted the casting of the awareness of the Chinese national community in Xinjiang.

\subsection{Cultivating Xinjiang People's Belief in the Value of Chinese Common Good Value}

In essence, the belief of common good value is an upward concept which is recognized and supported by the individuals in the community. This concept of common recognition is of great significance for the long-term existence of the community. On the one hand, different individuals can quickly condense and gradually recognize each other through the common value belief of common good; on the other hand, the common spiritual value and cultural heritage precipitate each other, creating belief guidance for the historical continuation of the community. As far as the Chinese national community is concerned, the value belief of common good is often displayed through the Chinese culture created and accumulated by all nationalities. Chinese culture is the result of the long-term integration of the Central Plains culture and the surrounding national cultures. All kinds of common good elements in the spiritual culture of all nationalities are concentrated in Chinese culture, providing the support of values and beliefs for the continuation of the common consciousness of the Chinese nation.

It is inevitable that religious culture plays an important role in the daily life of people of all ethnic groups in Xinjiang for a long time. During the Qing Dynasty, the Hezhuo family invaded the Kashgar region of Xinjiang several times. It was precisely by taking advantage of the noble position of the family among the Baishan believers that many bewitched farmers still believed in the correctness of following Hezhuo family to fight. Therefore, in the process of recovering Xinjiang led by Zuo Zongtang and Liu Jintang, in view of the fact that there were many ethnic groups in Xinjiang, and the languages and characters of each ethnic group had their own similarities and differences, they set up a wide range of private schools. Through the way of general education, they took the "Three Character Primer", "the Book of Family Names", "The Classic of Filial Piety" and other traditional cultural classics as carriers, so that the national common language could be mastered by more people. In order to maintain the normal operation of private schools, the provincial government specially allocated 28 taels of salary for teachers. As a result, the number of private schools in Xinjiang increased rapidly from 37 in 1880 to 77 in 1887 . The government of Xinjiang province would reward the excellent students and urge them to take the examination. When the time was right, the students would be recruited by the local government of Xinjiang. "Every year, all prefectures and counties will hold the examination. Those who are able to recite the classics and are familiar with the Chinese language, regardless of the number, will be sent to take a second examination. There is an example that the frontier officials recommend Wubian who will be given the official cap; and when he grows up, he will be the leader." $[14]^{89} \quad$ In addition, the provincial government would also give some awards to the local officials who set up the private schools, and take the development of culture and education as the performance standard to check whether the officials could be promoted, further promoting the enthusiasm of the principal officials in Xinjiang to develop culture and education.

After the establishment of the provincial system in Xinjiang, the local government spread Chinese culture widely and deeply through cultural education. In this process, the ideological and cultural identity among the people of all ethnic groups gradually increased, while the differences decreased. In particular, it deepened the belief of common good values of all ethnic groups based on the national common language, making the consciousness boundaries between the "self" and the "other" of many individuals of various nationalities gradually blurred and weakened, and enhancing the "sense of us". The vivid examples, such as Chinese pronunciation, deepened the consciousness of the Chinese national community of various nationalities.

\subsection{Practicing the Chinese Common Behavior Will of Xinjiang People}

Common behavior intention is the common expectation and practice of individuals in the community. What the community does is also what most individuals think. As an objective entity, the Chinese national community is not static, but composed of active individuals with practical will. Its internal free communication and the most basic 
life guarantee for self-realization are the manifestation of its individual subjective behavior will. However, if this common expectation is artificially blocked, the individual will not be able to obtain a new sense of reality and acquisition from the community, and this will also greatly frustrate the individual's cognitive experience of the community and weaken the recognition of the common good value belief.

In the Qing Dynasty, the policy of ethnic segregation was implemented for a long time in Xinjiang, which did not allow the people of different nationalities in the north and south to communicate with each other, and hinder the exchanges and integration of different nationalities. During the period of Yakub Beg's invasion of Xinjiang, the basic life of the people of all ethnic groups couldn't be guaranteed due to the long-term war, resulting in a great loss of population in Xinjiang. With the establishment of the provincial system in Xinjiang, in order to restore the normal population, the Qing government abolished the policy of ethnic segregation. In 1887, the Xinjiang Provincial Government issued the regulations of reclamation, and formulated a large number of preferential tax policies to attract labor force to Xinjiang. "Whether father and son work together, brothers live together or hire partners, they all take two people as a family, and each family will obtain $60 \mathrm{mu}$ of land." "The cost of silver is half in the first year, and all in the next year, and the amount of grain is collected from the third year and half, and all in the next year." [16] As a result, a large number of farmers from the mainland came to Xinjiang to reclaim wasteland or carry out business activities. "Han and Hui people of the mainland went to Xinjiang to work for food, reclamation and business" [17]. A large number of people from the mainland came to Xinjiang, and people of all ethnic groups in the northern and southern regions began to flow to each other to reclaim farmland in Xinjiang. Taking Dihua Suilai county (now Manas Town, Manas County, Xinjiang Uygur Autonomous Region) in the northern Xinjiang in the Qing Dynasty as an example, for Uygur households those who had no native place here, or those who were businessmen in Turpan or Tacheng, the officials had set a certain time for them, not allowing them to stay for a long time. After conquering the city in the reign of Guangxu, the people began to flow in. Today, there are about four or five hundreds of merchants, farmers and workers" [18]. Abolishing the policy of racial segregation enables the long suppressed common expectations to be realized in mutual communication. A steady stream of labor force came to Xinjiang, which also made Xinjiang's agriculture gradually recovered and further developed. In 1901, the population of Xinjiang reached more than 400000 households, with a total of more than 2 million people, which exceeded the highest level in Xinjiang history. The amount of cultivated land also reached a historical peak. The number of cultivated land in Northern Xinjiang increased from more than 1.2 million mu in Qianjia period to 2 million mu [19].

The abolition of racial segregation by the Qing government made the people of all ethnic groups in Xinjiang clear up many stereotypes and barriers in the process of mutual exchanges and blending. The vigorous cultivation of agriculture helped the people of all ethnic groups to meet their most basic life, and made the people of all ethnic groups form the direction of community behavior will in the process of meeting their living needs and exchanges and blending. At the same time, it gathered the action power of the Chinese nation, and the Qing government's many policies of benefiting the people also made the masses jointly manage a better life under the top-level design. This kind of action will provide a new sense of reality and vitality for the Xinjiang people of all ethnic groups to form the sense of Chinese national community.

\section{CONCLUSION}

Although the establishment of a provincial system in Xinjiang in 1884 came less than 30 years after the overthrow of the Qing Dynasty, the political unrest in Xinjiang was much less than that in frontier areas such as Tibet and Mongolia during this period. "A perceptive ma changes with the times, and a wise man changes with the society." Under the suggestion of Zuo Zongtang, the Qing government set up a provincial system in Xinjiang, where the border crisis was the most serious. This is not a simple change in the administrative system. The system strengthened the satisfaction and attribution of people of all ethnic groups living in the community of the Chinese nation, greatly improved the Chinese cognitive experience of the people of all ethnic groups in Xinjiang, and 
cultivated the value belief of the Chinese common good and practiced the Chinese common behavior will. And this is of great significance for the people of all ethnic groups in Xinjiang to cast a strong sense of the Chinese national community.

\section{AUTHORS' CONTRIBUTIONS}

Pengcheng Zeng wrote the manuscript, Linpeng Chen contributed to editing and revising.

\section{REFERENCES}

[1] Xi Jinping. Decision to build a well-off society in an all-round way to win the great victory of socialism with Chinese characteristics in the new era [N] People's Daily, 2017-10-28 (001).

[2] Wen Guang, Xu Yuanyuan. "An Outline of the Research on the Historical Process of the Formation and Development of the Chinese National Community Consciousness", "Ideological Front", Issue 2, 2018.

[3] Shen Guiping. "Building a Community with a Shared Future for the Chinese Nation Commemorating the 70th Anniversary of the Victory of the War of Resistance Against Japan", "Journal of Hunan Institute of Socialism", 2015, Issue 3.

[4] Qing Jue, Xu Xinshun. "Community Consciousness of the Chinese Nation: Conceptual Connotation, Element Analysis and Practical Logic", Ethnic Studies, Issue 6, 2018; Wang Jian. "Connotation of the Consciousness of Chinese Nation Community and Its Construction Path", "China National Education", Issue 4, 2018.

[5] Zhu Bibo. "On the Multidimensional Construction of the Chinese National Community", "Journal of Qinghai University for Nationalities", 2016, Issue 1; Dong Yanwei. "The Basic Connotation and Development Path of the Chinese National Community", "Climbing" Issue 2, 2019.

[6] Liu Jichang, Jin Binghao. "Building a Common Spiritual Homeland of All Nationalities and Cultivating the Consciousness of Chinese Nation
Community", "Journal of Southwest University for Nationalities", 2017 No.11.

[7] Chen Peng. "On the historical contribution of the formation of the Manchu community to the structure of the pluralistic unity of the Chinese nation", "Journal of Dalian Nationalities University", 2007, Issue 4.

[8] Ji Dachun. "The Establishment of Xinjiang in the Qing Dynasty" ("Xinjiang Social Science", 1984, Issue 4); Qi Qingshun. "The Establishment of Xinjiang Province and Its Historical Significance" ("The History of the Western Regions", Series 1, 1985); "The Great Victory of Xinjiang's Administrative System Reform in the Qing Dynasty Commemorating the 110th Anniversary of Xinjiang's Founding of a Province" ("Western Regions Studies", 1994, Issue 2); Wu Fuhuan. "An important measure for the modernization of China's border governance system - on Xinjiang's founding of "the province" ("Xinjiang University Journal", 1995, No. 4); Ji Yunfei. "A Commentary on the Establishment of Xinjiang in the Qing Dynasty" ("Journal of Jiangsu Administration", 2002, No. 2); "Zuo Zongtang and the Establishment of Xinjiang" ("Nanjing Social Sciences, 2003, Issue 6).

[9] (Qing Dynasty) Zuo Zongtang. Manuscript of Zuo Zongtang's Complete Works / Vol. 6 [M]. Yuelu Press, 1992, 4. (in Chinese)

[10] (Qing Dynasty) Zuo Zongtang. Manuscript of Zuo Zongtang's Complete Works / Vol. 7 [M]. Yuelu Press, 1992, 4. (in Chinese)

[11] (Qing Dynasty) Zhu Shoupeng (editor). Records of the Guangxu Period [M]. Beijing: Zhonghua Book Company, 1958.12. (in Chinese)

[12] Qing Jue, Xu Xinshun. The Chinese National Community Consciousness: Conceptual Connotation, Element Analysis and Practical Logic [J]. Ethnic Studies, 2018(06): 114+123. (in Chinese)

[13] Ji Aimin. An investigation of the construction of national identity based on the national perspective [M]. Beijing: Social Sciences Academic Press, 2016.12: 238. (in Chinese) 
[14] (Qing) Liu Jintang, Li Xubin, Yang Yunhui (check). Liu Jintang's and Li Xubin's memorials [M]. Changsha: Yuelu Press, 2013, 05. (in Chinese)

[15] (Qing Dynasty) Zuo Zongtang. Complete Works of Zuo Zongtang, Letter 3 [M]. Changsha: Yuelu Press, 1996, 07. (in Chinese) 356

[16] (Qing Dynasty) Yuan Dahua, Wang Shuke, Wang Xuezeng. Xinjiang Pictorial Records [M]. Shanghai: Shanghai Ancient Books Publishing House, 1992.10: 1921. (in Chinese)

[17] Cultural and Historical Data Committee, Enshi Ethnic and Religious Affairs Bureau Coedition of Hubei Province. Enshi Literature and History Data, 18th Series, Rao Yingqi Manuscript [M]. 2007.10: 101. (in Chinese)

[18] Research Center of Chinese Borderland History and Geography, Chinese Academy of Social Sciences. Xinjiang Local Records [M]. Beijing: National Library Document Microfilming Center, 1990.03: 136. (in Chinese)

[19] Cheng Chongde (editor in chief). Western Development in Qing Dynasty [M]. Taiyuan: Shanxi Ancient Books Publishing House, 2002: 157. (in Chinese) 